\title{
Contributions of auriculotherapy in smoking cessation: a pilot study*
}

\author{
CONTRIBUIÇÕES DA AURICULOTERAPIA NA CESSAÇÃO DO TABAGISMO: \\ ESTUDO PILOTO
}

\section{CONTRIBUCIONES DE LAAURICULOTERAPIA AL CESE DEL TABAQUISMO: ESTUDIO PILOTO}

\section{Roberta de Paiva Silva ${ }^{1}$, Erika de Cássia Lopes Chaves ${ }^{2}$, Sandra Cristina Pillon ${ }^{3}$, Andréia Maria Silva ${ }^{2}$, Denis da Silva Moreira ${ }^{4}$, Denise Hollanda lunes ${ }^{2}$}

\begin{abstract}
Objective: To evaluate the contribution of auriculotherapy in smoking cessation. Method: Double-blind randomized controlled trial, conducted with 30 smokers allocated into two groups: Experimental Group (21 participants received 10 sessions of auriculotherapy at specific points for smoking) and Control Group (nine participants received auriculotherapy in points that have no effect on the focus of research). Results: Auriculotherapy contributed in reducing the number of cigarettes smoked in $61.9 \%$ of participants $(p=0.002)$, in reducing the difficult to abstain from smoking in places where it is forbidden by $38 \%(p=0.050)$ and in not smoking when ill $23.8 \%(p=0.025)$. Conclusion: Given the efficacy only in terms of reducing the number of cigarettes smoked and other parameters, we suggest that future studies consider the use of auriculotherapy combined with other treatment methods, in order to achieve better results in cessation/abstinence.
\end{abstract}

\section{DESCRIPTORS}

Auriculotherapy

Smoking

Smoking cessation

Complementary therapies

\section{RESUMO}

Objetivo: Avaliar a contribuição da auriculoterapia na cessação do tabagismo. Método: Ensaio clínico controlado, randomizado e duplo cego conduzido com 30 tabagistas alocados em dois grupos: Grupo Experimental (21 participantes receberam 10 sessões de auriculoterapia em pontos específicos para o tabagismo) e Grupo Controle (nove participantes receberam a auriculoterapia em pontos que não possuem efeito sobre o foco de investigação). Resultados: O tratamento com auriculoterapia contribuiu na redução do número de cigarros fumados em $61,9 \%$ dos participantes $(p=0,002)$, na redução da dificuldade de ficar sem fumar em locais proibidos em $38 \%(p=0,050)$ e em não fumar quando doente em $23,8 \%(p=0,025)$. Conclusão: Diante da eficácia apenas em termos de redução do número de cigarros consumidos e dos demais parâmetros avaliados, sugere-se que trabalhos futuros considerem a utilização da auriculoterapia associada a outros métodos de tratamento, com intuito de alcançar melhores resultados de cessação/abstinência.

\section{DESCRITORES \\ Auriculoterapia \\ Hábito de fumar \\ Abandono do hábito de fumar \\ Terapias complementares}

\section{RESUMEN}

Objetivo: Evaluar la contribución de la auriculoterapia al cese del tabaquismo. Método: Ensayo clínico aleatorizado, controlado y doble ciego conducido con 30 tabaquistas dispuestos en dos grupos: Grupo Experimental (21 participantes recibieron 10 sesiones de auriculoterapia en puntos específicos para el tabaquismo) y Grupo Control (nueve participantes recibieron auriculoterapia en puntos que no tienen efecto sobre el foco de investigación). Resultados: El tratamiento con auriculoterapia contribuyó para la reducción de la cantidad de cigarrillos fumados en el $61,9 \%$ de los participantes $(p=0,002)$, la reducción de la dificultad de permanecer sin fumar en sitios prohibidos en el $38 \%(p=0,050)$ y en no fumar cuando enfermos en el $23,8 \%$ $(p=0,025)$. Conclusión: Ante la efectividad solo en términos de reducción de la cantidad de cigarrillos consumidos y los demás parámetros evaluados, se sugiere que trabajos futuros consideren la utilización de la auriculoterapia asociada con otros métodos de tratamiento, a fin de alcanzar mejores resultados de cese/abstinencia.

\section{DESCRIPTORES \\ Auriculoterapia \\ Hábito de fumar \\ Cese del tabaquismo \\ Terapias complementarias}

"Extracted from the dissertation "Efetividade da auriculoterapia na redução/cessação do tabagismo", Federal University of Alfenas, 2014. ${ }^{1}$ Master in Nursing, Federal University of Alfenas, Alfenas, MG, Brazil. ${ }^{2}$ Professor, Federal University of Alfenas, Alfenas, MG, Brazil. ${ }^{3}$ Full Professor, School of Nursing at Ribeirão Preto, University of São Paulo, Ribeirão Preto, SP, Brazil. ${ }^{4}$ Professor, Federal University of Alfenas, Alfenas, MG, Brazil. 


\section{INTRODUCTION}

The World Health Organization (WHO) estimates that in the twenty-first century, nearly one billion people will die from diseases caused by tobacco use ${ }^{(1)}$. Such use is characterized as health threat behavior, being considered a public health problem, since it is the second leading cause of morbidity and mortality in the world ${ }^{(2)}$. Furthermore, tobacco use and the burden of diseases associated with its use are growing, particularly in developing countries ${ }^{(2)}$.

In Brazil, the number of deaths occurred as consequences of smoking are higher than caused by alcoholism, AIDS, traffic accidents, homicides and suicides, reaching a rate of 200,000 deaths per year ${ }^{(3)}$. According to the Second National Survey of Alcohol and Drugs (LENAD) conducted in 2013, in 149 municipalities, involving 4,607 individuals of 14 years or more, found a prevalence of $19.3 \%$ of tobacco users. Considering national representativeness of the sample, one can estimate that there are, in Brazil, around 20 million smokers ${ }^{(4)}$.

The hazardous effects of smoking were shown to be associated with more than 50 types of diseases, not restricted to the respiratory system. Six of the eight leading causes of death have as a risk factor smoking, linked to several types of cancers (lung, larynx, kidney, bladder, stomach, cervix, oral cavity, esophagus), respiratory diseases (chronic bronchitis, Chronic Obstructive Pulmonary Disease - COPD), heart (ischemic heart disease, acute myocardial infarction), and abortion, infertility, male erectile dysfunction, reduced insulin sensitivity, increased propensity to psychiatric disorders, among other health problems ${ }^{(5)}$.

Given the intense problem that smoking involves, since the 1980s the Brazilian Ministry of Health is investing in the creation of laws, ordinances, decrees and resolutions to contain the spread of smoking in the country. Treatment of smoking cessation is offered by the Unified Health System (SUS), through various approaches (nicotine replacement therapy and motivational interventions) that are offered at all levels of complexity of health care ${ }^{(6)}$.

The current trend is to replace the models of care focused on illness, healing and drug intervention, by practices that promote the integrality of health care and involving preventive interventions, health promotion and the search for improved quality of life, such as integrative person-centered practices. Complementary therapies such as auriculotherapy, acupuncture and electrical stimulation have received little attention in research, although they are widely used in clinical practice, including for being considered safe and effective interventions in smoking cessation. Among the available therapies, we highlight auriculotherapy or ear acupuncture, a procedure of Traditional Chinese Medicine (TCM) focusing in the control and treatment of many diseases through stimulation of ear acupuncture points ${ }^{(7)}$.
When performing a peripheral stimulus on the network of blood and nerve flow, it generates an action potential, which transmits the nerve impulse to the thalamus and then cerebellum, brainstem, brain and all brain nuclei. Thus, sensitivity of auricular points triggers a series of biochemical phenomena related to each area of the body, thus getting streamlining of the energy balance process ${ }^{(7)}$.

In recent years, researchers have contributed to scientific research on a larger scale, in the context of systemic acupuncture compared to auriculotherapy. However, the evidence on auriculotherapy, which were conducted with appropriate methodological rigor, showed similar results to systemic technique, both in terms of clinical efficacy and the elements of neurophysiology(8).

Specifically for smoking, experimental studies have investigated the effects of auriculotherapy as an aid in smoking cessation ${ }^{(9-10)}$. However, we highlight that previous studies have had significant methodological limitations, including small sample sizes, lack of randomization, lack of blinding on the assessments, high dropout rates and outcomes that depend only on self-report ${ }^{(11)}$.

A meta-analysis ${ }^{(12)}$ concluded that auriculotherapy proved to be effective in smoking cessation, but the effect may not depend on the location point. A Systematic review also showed that there is no evidence free from methodological biases that acupuncture, laser therapy or electrostimulation are considered effective practices for smoking cessation ${ }^{(11)}$.It is worth noting scarcity of investment in research on the use of auriculotherapy for qualified healthcare professionals to develop this practice. Specifically, one may notice a few experimental studies evaluating the contribution of auriculotherapy in smoking cessation in the Brazilian scenario. Therefore, this study aimed to assess the contribution of the use of auriculotherapy in smoking cessation.

\section{METHOD}

This is a pilot study planned as double-blind randomized controlled trial, with workers from a public university in southern Minas Gerais, Brazil. The subjects were selected according to eligibility criteria: age $\geq 18$ years; smoking at least one cigarette per day; presenting level of exhaled carbon monoxide (COex) over six ppm (parts per million); expressing the desire to quit smoking; and having the availability of time to attend the sessions of auriculotherapy. Exclusion criteria: presence of infection, inflammation or injury in the ear; use of piercing in the ear (except regular earring); participate in other treatment for smoking cessation (medicated or not); be in gestational period; and does not show in two or more consecutive sessions.

When considering the eligibility criteria, the sample was initially composed of 35 subjects divided by stratified randomization (the degree of dependence of the
Contributions of auriculotherapy in smoking cessation: a pilot study Silva RP, Chaves ECL, Pillon SC, Silva AM, Moreira DS, lunes $D H$ 
initial nicotine) and divided into two groups: Experimental Group ( 24 individuals) and Control Group (11 subjects). In the course of implementing the intervention, the initial sample of 35 individuals, five were removed as exclusion criteria (consecutive no show in two or more sessions). Thus, the sample consisted of 30 individuals: Experimental Group (21 who received auriculotherapy at specific points for tobacco control) and Control Group (nine receiving auriculotherapy in points considered irrelevant to tobacco control and that do not cause health risk).

The data collection instrument is composed of three parts: 1) demographic information, 2) Fagerstrom Test for Nicotine Dependence (FTND), and 3) A Form to monitor the intervention. Sociodemographic information refer to gender, age, marital status, housing, personal income, presence of disease, be undergoing behavioral therapy and practice of physical activity.

FTND is a test to measure the level of severity of tobacco dependence, developed by Karl-Olov Fagerstrom in 1978, based on the Fagerstrom Tolerance Questionnaire $(\text { FTQ) })^{(13)}$. In 1991, after its adaptation, it was renamed to Fagerstrom Test for Nicotine Dependence ${ }^{(14)}$.

In Brazil, FTND was translated and validated by Carmo and Pueyo ${ }^{(15)}$, who identified an index of internal consistency of 0.642, a similar result to the English (0.61), French (0.70), Spain (0.66) and Dutch (0.71) versions. In a Brazilian study of test-retest correlation, it was found a Cronbach's alpha of 0.915 , close to the French transcultural adaptation $0.85^{(15)}$, which facilitates its use.

FTND consists of six items, which refer to the difficulty to abstain from smoking in forbidden places and when bedridden by illness, the number of cigarettes smoked, the time taken after waking up to smoke the first cigarette, if the first cigarette in the morning is the one which brings more satisfaction and whether the individual smokes more in the early morning hours. The response items from the first to the sixth questions range from zero to three points and the other items, from zero to one. The sum of total of points is equal to 10 , so the dependence is classified as: ( 0 - 2 points) very low dependence; ( $3-4$ points) low dependence; (5 points) medium dependence; (6 - 7 points) high dependence; and ( 8 - 10 points) very high dependence ${ }^{(15)}$.

The form used for monitoring the intervention contains information about the perceived adverse reactions during or after the sessions, number of cigarettes smoked (NCS) at the beginning and end of the intervention, degree of nicotine dependence (DND) obtained by FTND and COex measured at baseline and at the end of the fifth and seventh session, at the end of treatment (tenth session) and at follow-up (30 days after the last session).

COex was measured by the monoximeter, a device that measures the concentration of expired CO by an electrochemical sensor, expressing it in parts per million (ppm).
For this measurement was asked to participants inspire their total lung capacity (ambient air) then make an inspiratory pause of 15 seconds, so that the $\mathrm{CO}$ in the blood could come into equilibrium with the alveolar air, allowing the device to estimate, with better accuracy, the concentration of $\mathrm{CO}$ in the blood from COex. After this interval, participants were instructed to exhale slowly and completely in the mouthpiece of the device. Values above six ppm of COex were considered significant for smoking, as evidenced in the literature ${ }^{(16)}$.

COex measurements were standardized to be always performed at the same time of the day, in order to minimize the effects of the number of cigarettes smoked on the result, ensuring that the interval between the last smoked cigarette and COex measurement, as well as the number of cigarettes smoked since the last measurement. They were similar in all evaluations, considering smoking to be related to routine habits.

\section{Application of auriculotherapy}

In auriculotherapy, mustard seeds were used. The procedure was applied by nursing professionals who are specialized in auriculotherapy, with ear acupuncture points of the Chinese board ${ }^{(7)}$. Two weekly sessions were held for five weeks, totaling 10 sessions, alternating auricles each session.

Before starting the procedure with the placement of the mustard seed, the auricle was cleaned with alcohol $70 \%$. The seed was stuck in the ear with tape, the participant was asked to stimulate the points three times daily. Possible discomforts related to pain at the site, and the presence of adverse effects were reported to study participants.

Ear points were determined according to the literature, for the experimental group were: Shenmen, Kidney, Sympathetic, Anxiety 1, Anxiety 2, Hunger, Thirst and Addictions. For the Control Group, the points stimulated, considered irrelevant to tobacco control were Elbow and Arm. Two points were determined for the Control Group, with a view to stimulating a greater number of points, chosen randomly without therapeutic purposes, causing energy imbalance in the individual ${ }^{(7)}$. Participants were instructed that there were other people who were undergoing the procedure, but with a different seed number in the ear.

Assessment procedures were performed in session zero, called initial assessment (baseline), $5^{\text {th }}$ session, $7^{\text {th }}$ session, $10^{\text {th }}$ session (end) and 30 days after completion of treatment (follow-up).

It is noteworthy that the blinding of the strategies used for data collection was conducted. Thus, the professional who applied the procedure for placing the seeds did not perform assessment procedures. The evaluator did not know which group the patient belonged and did not know which treatment the patient was receiving active or placebo. 


\section{Analysis of results}

A database was initially developed in a spreadsheet (Microsoft Office Excel 2007) and later in the Statistical Package for Social Science (SPSS) version 17 for Windows. The results were described in tables with percentages and absolute frequencies. Chi-square test $\left(\chi^{2}\right)$ was used to verify independence between demographic, clinical and pattern of tobacco use variables, according to the Experimental and Control Groups. In situations of expected values smaller than five, Fisher's exact test was used.

To check the adherence of the data distribution to normality, we used the Shapiro-Wilk test. After this test, to determine the association between qualitative and quantitative variables, with description of two groups, we used the Student t-test by the presence of normality and the Mann-Whitney test in the absence of normality. Faced with a lack of normal distribution, Wilcoxon test was used to evaluate a given variable at different moment. We adopted a significance level of $5 \%$ for all tests.

\section{Ethical aspects}

In order to ensure the rights of participants and meet the aspects contained in Resolution 466/2012 of the Brazilian Ministry of Health, the project was approved by the Ethics in Research involving Humans (CAAE: 08777112.9.0000.5142). It was also held the registration of study in Brazilian Clinical Trials Registry (Rebec) platform, under approved number RBR-3xktv5.

\section{RESULTS}

\section{Sociodemographic information}

We observed homogeneity of the sample in all investigated variables between the Experimental and Control Group. The sample was characterized by adults with a mean age of 41 years old, female (66.7\%), married (70\%), living with family $(96.6 \%)$, with income of up to five minimum wages $^{\text {a }}(90 \%)$, reporting an illness $(70 \%)$ had no history of behavioral therapy (86.7\%) and non-practicing of physical activities (63.3\%).

\section{Pattern of tobacco consumption}

Tobacco consumption at the beginning and end of treatment are presented in Table 1. We observed that, initially, the groups were homogeneous regarding the consumption of tobacco and at the end of treatment, no significant differences were found between the experimental and control group.

It is observed in Table 1 that there was a gradual reduction of most indicators evaluated throughout the intervention period for both groups. However, the mean are

a The minimum wage in Brazil corresponds to $R \$ 724,00$ reais or $U \$ 323,27$ dollars according to the Central Bank of Brazil on August 30th, 2014. clinically lower in the Experimental Group, mainly related to the level of COex, for which the level remained unchanged from the end of treatment for the Control Group, unlike the Experimental Group, which showed a mean difference reduction of $4.11 \mathrm{ppm}$.

Table 1 - Tobacco use (mean - $\bar{x}$ and standard deviation - SD) at baseline and at the end for the Experimental and Control Group - Minas Gerais, 2014

\begin{tabular}{lcccc}
\hline Variables & & $\begin{array}{c}\text { Experimental } \\
\bar{x} \pm \mathrm{dp}\end{array}$ & $\begin{array}{c}\text { Control } \\
\bar{x} \pm \mathrm{dp}\end{array}$ & p-value \\
\hline \multirow{4}{*}{ Baseline } & DND & $3,2 \pm 1,3$ & $3,9 \pm 1,6$ & 0,226 \\
& COex & $18,4 \pm 7,1$ & $16,7 \pm 4,3$ & 0,657 \\
& NCS & $18,2 \pm 6,2$ & $17,1 \pm 5,6$ & 0,657 \\
\hline \multirow{3}{*}{ End } & DND & $2,2 \pm 1,1$ & $2,7 \pm 1,6$ & 0,563 \\
& COex & $14,3 \pm 7,0$ & $16,7 \pm 4,4$ & 0,114 \\
& NCS & $11,2 \pm 7,0$ & $11,3 \pm 6,0$ & 0,790 \\
\hline
\end{tabular}

Mann-Whitney test; DND: Degree of Nicotine dependence; COex: carbon monoxide in exhaled air; NCS: Number of cigarettes smoked.

\section{Number of cigarettes smoked}

As for the NCS throughout the study, we observed that there were no statistically significant differences between groups. However, it was found that the Experimental Group had 1.2 times more reduction of NCS at the end of treatment, as well as participants in the Control Group returned to smoking, on average, three cigarettes after a month of the end of the sessions, while Experimental Group remained the same at the end of treatment (Table 2).

Table 2 - Number of cigarettes smoked during the study (NCS), mean differences between Experimental and Control Group Minas Gerais, 2014

\begin{tabular}{lcccc}
\hline NCS vs Groups & & $\begin{array}{c}\text { Mean } \\
\text { difference }\end{array}$ & $\begin{array}{c}\text { Standard } \\
\text { error }\end{array}$ & p-value \\
\hline $\begin{array}{l}\text { End versus } \\
\text { baseline }\end{array}$ & Experimental & $-7,0$ & 1,4 & \multirow{2}{*}{0,648} \\
\hline $\begin{array}{l}\text { Follow-up } \\
\text { versus End }\end{array}$ & Control & $-5,7$ & 2,5 & \\
\hline
\end{tabular}

Student's t-test.

When evaluating the number of cigarettes smoked per day (FTND), it was found that, at the end of the five-week intervention, 13 participants in the Experimental Group (61.9\%) had negative positions, that is, the NCS was significantly lower when end of therapy $(p=0.002)$, with a reduced variation of one to 23 cigarettes. However, in the Control Group, the reduction rate of $33.3 \%$ (three subjects) was not significant $(p=0.102)$, ranging from two to 20 cigarettes.

\section{Degree of nicotine dependence}

Table 3 shows levels of severity of nicotine dependence during the study period. No significant differences were observed between the groups, since there was DND reduced in both groups. 
Table 3 - Degree of nicotine dependence (DND) during the study, mean difference in the Experimental and Control Group Minas Gerais, 2014

\begin{tabular}{llccc}
\hline DND vs Grups & & $\begin{array}{c}\text { Mean } \\
\text { difference }\end{array}$ & $\begin{array}{c}\text { Standard } \\
\text { error }\end{array}$ & p-value \\
\hline $\mathbf{5}^{\text {th }}$ session & Experimental & -0.6 & 0.1 & 0.133 \\
versus baseline & Control & -1.1 & 0.4 & \\
$\boldsymbol{7}^{\text {th }}$ session & Experimental & -0.9 & 0.1 & 0.678 \\
versus baseline & Control & -0.7 & 0.4 & \\
End versus & Experimental & -1.0 & 0.2 & 0.704 \\
baseline & Control & -1.2 & 0.4 & \\
Follow-up & Experimental & -0.9 & 0.2 & 0.446 \\
versus baseline & Control & -0.5 & 0.5 & \\
Follow-up & Experimental & 0.1 & 0.1 & 0.136 \\
versus End & Control & 0.6 & 0.3 & \\
\hline Student's t-test. & & & &
\end{tabular}

By analyzing the levels of dependence presented in Table 4, we found no significant differences between groups at baseline, end and follow-up assessments. However, we observed the presence of important clinical findings, since the Experimental Group, at baseline had 10 participants (47.6\%) with very high degree of dependence and, at the end of treatment, this index decreased for three subjects (14.3\%), as well as the reduction in the Control Group was seven (77.7\%) for three subjects (33.3\%).

\section{Exhaled carbon monoxide (COex)}

In COex evaluation during treatment, we observed in Table 5 a difference of six ppm between the groups for the association between follow-up and baseline $(p=0.021)$. This means that the Experimental Group reduced about $3.6 \mathrm{ppm}$ of Coex, while the control group increased the level of $2.4 \mathrm{ppm}$. We highlight all associations in larger reduction of COex levels during the sessions for the Experimental Group.

Table 5 - Exhaled carbon monoxide (COex) during the study and mean difference of the Experimental Group and Control - Minas Gerais, 2014

\begin{tabular}{llccc}
\hline COex vs Groups & & $\begin{array}{c}\text { Mean } \\
\text { difference }\end{array}$ & $\begin{array}{c}\text { Standard } \\
\text { error }\end{array}$ & p-value \\
\hline $\mathbf{5}^{\text {th }}$ session & Experimental & -3.5 & 2.2 & 0.224 \\
versus baseline & Control & -0.4 & 1.1 & \\
$\boldsymbol{7}^{\text {th }}$ session & Experimental & -2.7 & 1.6 & 0.198 \\
versus baseline & Control & 0.8 & 1.6 & \\
End versus & Experimental & -4.1 & 1.7 & 0.172 \\
baseline & Control & -0.1 & 1.8 & \\
Follow-up & Experimental & -3.6 & 1.4 & \multirow{2}{*}{$0.021^{*}$} \\
versus baseline & Control & 2.4 & 1.8 & \\
Follow-up & Experimental & 0.5 & 0.9 & 0.246 \\
versus End & Control & 2.5 & 1.1 & \\
\hline Student's t-test; * p-value $\leq 0,05$. & & &
\end{tabular}

Table 4 - Description of the degree of severity of nicotine dependence - Minas Gerais, 2014

\begin{tabular}{|c|c|c|c|c|c|c|c|c|}
\hline \multirow{2}{*}{\multicolumn{2}{|c|}{ Variable }} & \multicolumn{2}{|c|}{ Experimental $(n=21)$} & \multicolumn{2}{|c|}{ Control $(n=9)$} & \multicolumn{2}{|c|}{ Total $(\mathbf{n}=\mathbf{3 0})$} & \multirow{2}{*}{ p-value } \\
\hline & & f & $\%$ & f & $\%$ & f & $\%$ & \\
\hline \multirow[t]{5}{*}{ Baseline } & Very low & 2 & 9.5 & - & - & 2 & 6.7 & \multirow{3}{*}{0.260} \\
\hline & Low & 5 & 23.8 & 2 & 22.2 & 7 & 23.3 & \\
\hline & Medium & 4 & 19.0 & - & - & 4 & 13.3 & \\
\hline & High & 6 & 28.6 & 4 & 44.4 & 10 & 33.3 & \multirow{2}{*}{0.260} \\
\hline & Very high & 4 & 19.0 & 3 & 33.3 & 7 & 23.3 & \\
\hline \multirow[t]{2}{*}{ End } & Very low & 7 & 33.3 & 3 & 33.3 & 10 & 33.3 & \multirow{2}{*}{0.563} \\
\hline & Low & 7 & 33.3 & 2 & 22.2 & 9 & 30.0 & \\
\hline \multirow[t]{3}{*}{ End } & Medium & 4 & 19.0 & 1 & 11.1 & 5 & 16.7 & \multirow{3}{*}{0.563} \\
\hline & High & 2 & 9.5 & 1 & 11.1 & 3 & 10.0 & \\
\hline & Very high & 1 & 4.8 & 2 & 22.2 & 3 & 10.0 & \\
\hline \multirow[t]{5}{*}{ Follow-up } & Very low & 6 & 28.6 & 3 & 33.3 & 9 & 30.0 & \multirow{5}{*}{0.107} \\
\hline & Low & 8 & 38.1 & - & - & 8 & 26.7 & \\
\hline & Medium & 3 & 14.3 & 2 & 22.2 & 5 & 16.7 & \\
\hline & High & 2 & 9.5 & - & - & 2 & 6.7 & \\
\hline & Very high & 2 & 9.5 & 3 & 33.3 & 5 & 16.7 & \\
\hline
\end{tabular}

Teste Mann-Whitney.

There were clinical differences at the end of the treatment between groups, since the Experimental Group reduced an average of $4.1 \mathrm{ppm}$ of COex, whereas in the Control Group the mean difference was $0.1 \mathrm{ppm}$.

\section{Fagerstrom test for nicotine dependence}

Three aspects addressed by FTND presented significant changes during treatment with auriculotherapy in the experimental group. We evidenced by the comparison between end and baseline that $38 \%$ of participants in the Experimental Group did not present difficulties in abstaining from smoking in forbidden places, at the end of treatment $(p=0.050)$. Also $23.8 \%$ of the participants in the Experimental Group reported that they did not smoke when bedridden by illness, at the end of the study ( $p=$ 0.025 ) and $61.9 \%$ for the number of cigarettes smoked per day was lower at the end of treatment $(p=0.002)$.

\section{DISCUSSION}

This study aimed to assess the contribution of the use of auriculotherapy in smoking cessation. We found that the use of auriculotherapy for smoking cessation contributed to reducing the NCS and COex, indicating the positive effect 
of this technique with the proposed methodology. However, there was no complete cessation of smoking, which may be related to study characteristics, such as treatment time, material used for auriculotherapy and the protocol chosen.

Some limitations can be pointed for this research, such as the small number of subjects, lack of randomization and sample calculation. Therefore, further studies are needed with larger sample, to know the effect of the application of auriculotherapy in smoking cessation. Such studies are still scarce, particularly in relation to treatment protocols. The available studies ${ }^{(9-10,17)}$ tested various forms of treatment with different methodologies, which resulted in different results.

In the present study, the application of auriculotherapy used mustard seeds as they are not invasive and participants have higher tolerance ${ }^{(18)}$, however, there is also evidence of a positive result with the use of needles. Study ${ }^{(19)}$ that tested the applicability of auriculotherapy comparing the use of needles and seeds to assess the reduction of stress in nurses showed important contributions of this technique in reducing stress. The best results were obtained by the group that used needles, since it was not necessary to stimulate ear points ${ }^{(19)}$.

Regarding the pattern of tobacco use in the present study, we observed a variation in the reduction of one to 23 cigarettes among participants in the Experimental Group, expressive value, since the mean cigarettes smoked at the start of treatment was 18 . Thus, even if we did not achieved smoking cessation, participants have substantially reduced the number of cigarettes smoked.

The finding in terms of reduction in cigarette use, in this study, suggests that the technique can bring positive benefits to worker health. A prospective cohort study ${ }^{(20)}$, conducted with 4,633 male workers who were smokers, found that reducing the number of cigarettes smoked per day may reduce by $15 \%$ the risk of mortality and $23 \%$ the risk of mortality from cardiovascular problems.

Given the results of this study, as well as the evidence found in the literature, one can reflect on the use of auriculotherapy combined with other treatment methods. The association of auriculotherapy with other types of intervention of motivational nature may enhance the benefits in individuals who are trying to quit smoking.

In this context, the authors also argue that the absence of motivational strategies and practical counseling ${ }^{(21)}$ negatively interfere in smoking cessation. Study that evaluated the effects associated with the application of intensive motivational counseling obtained as a result a reduction of $89.7 \%$ in smoking cessation in the first week of auriculotherapy ${ }^{(22)}$. Study using counseling and motivational strategies suggest the need for inclusion and expansion of the variables associated to therapeutic treatments ${ }^{(23)}$.

In line with the reduction of NCS, we showed that the Experimental Group reduced an average of $4.1 \mathrm{ppm}$ COex.
This result shows the potential of clinical applicability and good correlation between the methods of assessment of smoking (behavioral and biological marker). Biological methods have great advantage over the others, by the excellent accuracy and objectivity. Specifically, measurement of COex is a cost effective method, which allows us to offer immediate feedback to the individual, thus it has been employed in programs addressing smoking, promoted by government agencies.

The FTND is a widely used instrument in clinical practice and research ${ }^{(5)}$. This study identified changes in smoking habits, since detected shifts in difficult to abstain from smoking in places where it is forbidden to smoke, smoke even if ill and the number of cigarettes smoked per day, with significant differences to the Experimental Group, reinforcing that auriculotherapy can contribute in reducing the number of cigarettes smoked.

It is worth noting that smoking is a causal factor of various diseases and currently accounts for $30 \%$ of all cancer deaths, $85 \%$ of deaths from COPD (emphysema), $30 \%$ of deaths from cerebrovascular disease and $45 \%$ of deaths from cardiovascular diseases ${ }^{(24)}$. Therefore, the fact that a portion of the study participants have reduced smoking when ill, is an important achievement, compared to the magnitude of the consequences of smoking. Many people smoke because of nicotine dependence and sometimes the consequences of this habit is only observed over time.

\section{CONCLUSION}

In this study, a pioneer in Brazil on the subject investigated, the treatment with auriculotherapy helped in reducing the number of cigarettes smoked for $61.9 \%$ of participants, reducing the difficulty to abstain from smoking in places where it is forbidden to smoke for $38 \%$ and not smoking when ill for $23.8 \%$. However, it does not mean that smoking has ceased completely. As quitting smoking remains a challenge due to its complex and multifactorial factors, involving biological, psychological and behavioral aspects.

A strong point of this study refers to the reduction in the number of cigarettes smoked, implying increased survival and improvement in various aspects of quality of life of smokers. Therefore, it is suggested that future studies consider this contribution associated with other ways of treatment, including the assessment of motivational state before the start of treatment and promote counseling and motivational strategies in order to achieve better results in the cessation/withdrawal.

The present study has some limitations. One of them is related to sample size, with a small number of participants. Thus, it is considered timely to conduct studies with larger samples and in other healthcare environments, such as specialized centers for the treatment of chemical depen-
Contributions of auriculotherapy in smoking cessation: a pilot study Silva RP, Chaves ECL, Pillon SC, Silva AM, Moreira DS, lunes $D H$ 
dence. Also, another important limitation concerns the assessment of comorbidities, such as the presence of depression and anxiety, which were not evaluated in this study.
We conclude that the use of the technique of auriculotherapy can bring important contributions as a complementary therapy in tobacco control.

\section{REFERENCES}

1. World Health Organization. WHO Report on the global tobacco epidemic, 2011 [Internet]. Geneva: WHO; 2011 [cited 2014 May 15]. Available from: http://www.who.int/tobacco/ global_report/2011/en/

2. World Health Organization. Global health risks: mortality and burden of disease attributable to selected major risks [Internet]. Geneva: WHO; 2009 [cited 2014 May 15]. Available from: http://www.who.int/healthinfo/global_burden_ disease/GlobalHealthRisks_report_full.pdf

3. World Health Organization. WHO report on the global tobacco epidemic, 2008: the MPOWER package [Internet]. Geneva: WHO; 2008 [cited 2014 May 15]. Available from: http://www. who.int/tobacco/mpower/mpower_report_full 2008.pdf

4. Instituto Nacional de Políticas Públicas do Álcool e Outras Drogas (INPAD). II Levantamento Nacional sobre Álcool e Drogas - II LENAD [Internet]. Brasília; 2013 [citado 2014 maio 12]. Disponível em: http://inpad.org.br/lenad/

5. Castro MRP, Nunes SOV, Faria DD, Rocha CEB, Bacchi RS. A dependência da nicotina associada ao uso de álcool e outras substâncias psicoativas. Semina Ciênc Biol Saúde [Internet]. 2008 [citado 2014 maio 12];32(2):131-40. Disponível em: http://www.uel.br/revistas/uel/index.php/seminabio/article/ viewFile/3461/2816

6. Pinto M, Ugá MAD. Os custos de doenças tabaco-relacionadas para o Sistema Único de Saúde. Cad Saúde Pública. 2010;26(6):1234-45.

7. Souza MP. Tratado de auriculoterapia. Brasília: LooK; 2012.

8. Niemtzow RC, Oleson T. Development of auriculotherapy around the world. Med Acupunct [Internet]. 2014 [cited 2014 May 12];26(2):74-5. Available from: http://online.liebertpub. com/doi/pdf/10.1089/acu.2014.2622

9. Wu TP, Chen FP, Liu JY, Lin MH, Hwang SJ. A randomized controlled clinical trial of auricular acupuncture in smoking cessation. J Chin Med Assoc. 2007;70(8):331-8.

10. Fritz DJ, Carney RM, Steinmeyer B, Ditson G, Hill N, ZeeCheng J. et al. The efficacy of auriculotherapy for smoking cessation: a randomized, placebo-controlled trial. J Am Board Fam Med. 2013;26(1):61-70.

11. White AR, Rampes H, Liu JP, Stead LF, Campbell J. Acupuncture and related interventions for smoking cessation. Cochrane Database Syst Rev. 2011;(1): CD000009.
12. White A, Moody R. The effects of auricular acupuncture on smoking cessation may not depend on the point chosen-an exploratory metaanalysis. Acupunct Med [Internet]. 2006 [cited 2014 May 12];24(4):149-56. Available from: http:// acupmed.bmjjournals.com/content/24/4/149.full.pdf+html

13. Fagerström KO. Measuring degree of physical dependence to tobacco smoking with reference to individualization of treatment. Addict Behav. 1978;3(3-4):235-41.

14. Heatherton TF, Kozlowski LT, Frecker RC, Fagerström KO. The Fagerström Test for Nicotine Dependence: a revision of the Fagerström Tolerance Questionnaire. $\mathrm{Br} J$ Addict. 1991;86(9):1119-27.

15. Carmo JT, Pueyo AA. A adaptação ao português do Fagerström Test for Nicotine Dependence (FTND) para avaliar a dependência e tolerância à nicotina em fumantes brasileiros. Rev Bras Med. 2002;59(1-2):73-80.

16. Oliveira MVC, Oliveira TR, Pereira CAC, Beserra MR, Silva EM, Fonseca VAS. Tabagismo em pacientes internados em um hospital geral. J Bras Pneumol. 2008; 34(11):936-41.

17. Kang HC, Shin KK, Kim KK, Youn BB. The effects of the acupuncture treatment for smoking cessation in high school student smokers. Yonsei Med J. 2005;46(2):206-12.

18. Suen LKP, Thomas KSW, Leung AWN. Auricular therapy using magnetic pearls on sleep: a standardized protocol for the elderly with insomnia. Clin Acupunct Oriente Med [Internet]. 2002 [cited 2014 May 12];3(1):39-50. Available from: http://www.sciencedirect.com/science/article/pii/ S1461144901901136

19. Kurebayashi LFS, Gnatta JR, Borges TP, Belisse G, Coca S, Minami $A$, et al. The applicability of auriculotherapy with needles or seeds to reduce stress in nursing professionals. Rev Esc Enferm USP[Internet]. 2012 [cited 2014 May 16];46(1):89-95. Available from: http://www.scielo.br/pdf/ reeusp/v46n1/en_v46n1a12.pdf

20. Gerber Y, Myers V, Goldbourt U. Smoking reduction at midlife and lifetime mortality risk in men: a prospective cohort study. Am J Epidemiol. 2012;175(10):1006-12.

21. Santos JDP, Silveira DV, Oliveira DF, Caiaffa WT. Instrumentos para avaliação do tabagismo: uma revisão sistemática. Ciênc Saúde Coletiva. 2011;16(12):4707-20. 
22. Thanavaro JL, Delicath TA. Auricular transcutaneous electrostimulation therapy and intensive counseling for the treatment of smoking cessation in a primary care practice. J Addict Nurs. 2010;21(4):215-24.

23. Pamplona $\mathrm{P}$, Mendes B. Estratégia de tratamento do tabagismo na DPOC. Rev Port Pneumol. 2009;15(6):1121-56.
24. Brasil. Ministério da Saúde; Instituto Nacional de Câncer. Tabagismo um grave problema de saúde pública. Rio de Janeiro: INCA; 2007.

\section{Financial support}

Conselho Nacional de Desenvolvimento Científico e Tecnológico (CNPq), Process/CNPq 477383 / $2012-2$. 